\title{
Self-medication and self-prescription
}

\author{
Alberto Lifshitz, Oscar Arrieta, Rubén Burgos, Carlos Campillo, Miguel Á. Celis, \\ Manuel de la Llata, Judith Domínguez, José Halabe, Sergio Islas, Luis Jasso, \\ Mucio Moreno, Ricardo Plancarte, Alejandro Reyes-Sánchez, Guillermo Ruiz-Argüelles, Antonio Soda, \\ Emma Verástegui and Julio Sotelo* \\ Comité de Ética y Transparencia en la Relación Médico-Industria, Academia Nacional de Medicina de México, Mexico City, Mexico
}

\begin{abstract}
Self-medication and self-prescription are actions undertaken by patients; the former, as an element of self-care that involves overthe-counter drugs, and the latter, as a violation of the Statute of Health, since it includes drugs that can only be dispensed with a medical prescription. All the drawbacks that have been attributed to self-medication are actually associated with self-prescription.
\end{abstract}

KEY WORDS: Self-medication. Self-prescription. Self-care. Free sale. OTC medications.

\section{Automedicación y autoprescripción}

\section{Resumen}

La automedicación y la autoprescripción son acciones de los pacientes; la primera como elemento del autocuidado que involucra medicamentos de venta libre y la segunda como una violación a la ley de salud, pues comprende medicamentos que solo pueden expenderse con receta. Todos los inconvenientes que se han atribuido a la automedicación en realidad lo son de la autoprescripción.

PALABRAS CLAVE: Automedicación. Autoprescripción. Autocuidado. Venta Libre. Medicamentos OTC.

Self-medication has been criticized by doctors, who consider it to be an inappropriate practice to which harmful consequences are attributed, such as contributing to medical care delay, increasing the frequency of drug adverse effects, masking symptoms and others. Paradoxically, the World Health Organization recognizes that health self-care is an important resource of medical care, which includes non-pharmacological care, healthy lifestyles, social support in disease and early management of superficial discomforts with self-medication. In the COVID-19 pandemic, the health authority has recommended self-medication at home for mild symptoms. This apparent contradiction surely is the result of a terminological confusion, when the term self-medication is used to refer to self-prescription. Regarding this confusion, the Committee of Ethics and Transparency in the Physician-Industry Relationship (CETREMI - Comité de Ética y Transparencia en la Relación MédicoIndustria) ${ }^{1}$ issues the following recommendations:

For marketing purposes, the health authority classifies drugs into six groups (article 226 of the General Statute of Health):

I) Those that can only be acquired with a prescription and special permission.

II) Those whose prescription is retained by the pharmacy.

III) Those whose prescription can be filled up to three times.

\footnotetext{
Correspondence: Date of reception: 22-06-2020

*Julio Sotelo_ Date of acceptance: 25-06-2020

E-mail: jsotelo@unam.mx DOI: 10.24875/GMM.M21000456

Gac Med Mex. 2020;156:600-602

Contents available at PubMed

0016-3813/@ 2020 Academia Nacional de Medicina de México, A.C.. Published by Permanyer. This is an open access article under the CC BY-NC-ND license (http://creativecommons.org/licenses/by-nc-nd/4.0/).
} 
Table 1. Over-the-counter medications characteristics

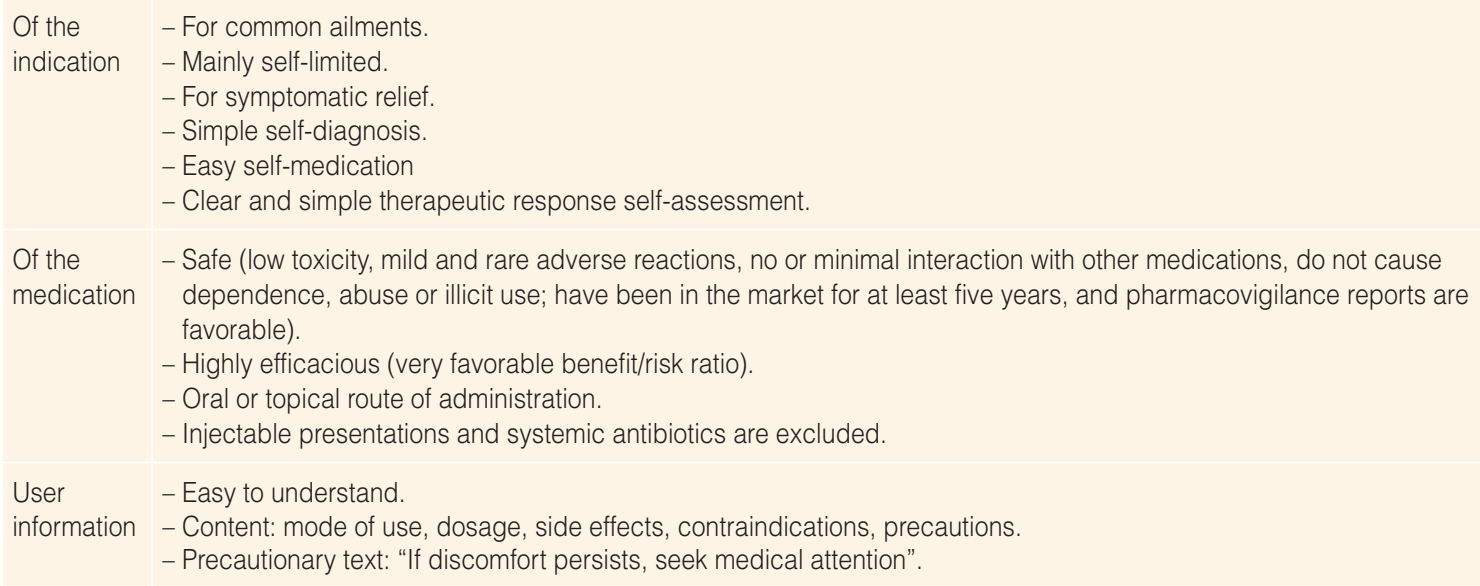

IV) Those that require a prescription, but it can be refilled.

V) Those that do not require a prescription, but are sold only in pharmacies.

VI) Those that do not require a prescription and can be sold in establishments other than pharmacies.

Self-medication refers to the use of drugs in groups $\mathrm{V}$ and VI without the need for a prescription or doctor recommendation, while self-prescription refers to the use of drugs in groups I, II, III and IV. In short, self-medication is the use of drugs authorized to be employed without a prescription, and self-prescription implies an infringement of the law and being exposed to a clear risk owing to the nature of the products that are used. Medicines in groups $\mathrm{V}$ and $\mathrm{VI}$ are referred to as "nonprescription" or "over the counter", or OTC products. Table 1 shows the characteristics of these products.

Medicines that should be sold only by prescription (groups I to IV) lack information for their use on the containers or labels, since it is deemed that doctors prescribe them and it is assumed that they consult the prescribing information (PI). Although, theoretically, this information is not publicly accessible, access to drug information for healthcare professionals, different pharmacopeias and the Internet is increasingly unrestricted. The text "Dosage: as directed by the physician" is mentioned. ${ }^{2}$ In OTC medications, information on dosage and precautions is mandatory. Some pharmaceutical companies have adopted the strategy of advertising directly to the user in order for him/her to press the doctor.

\section{Role of the patient}

The idea that people can self-medicate for minor ailments is not shared by all physicians, but is part of a movement known as "patient emancipation", which is based on the individual capacity to make decisions in the exercise of autonomy. The physician's position, which is supported by the principle of beneficence, is opposed to self-medication in many of them. Tradition starts from the idea that patients may not make appropriate decisions, and that the doctor has to make them to their benefit in a paternalistic, sometimes authoritarian, and others benevolent exercise. Some physicians are against self-medication because their source of income regarding the care of minor ailments is threatened, and thus they do not favor patient independence and promote and maintain dependence, as it occurs, for example, with chronically ill patients.

Currently, telephone counseling, anathematized in the past, has been vindicated, and electronic counseling has been added; the concept of "expert patient" is accepted, self-help groups are promoted and some patients are found to know more about their disease than their physicians. In the doctor-patient relationship model, called "of association" or "collegiate", the doctor is an expert on the disease and the patient is an expert in his/her condition and, together, they choose and implement the best alternatives.

Currently, the right of the patient to participate in the decisions that are of his/her concern and not only to act as an obedient processor of orders is recognized. From this perspective, patients are granted prerogatives such as using OTC medications and identifying the need to seek medical attention, either urgent, by 
telephone, or scheduled; selecting the care that is suitable for them (including alternative medicine) and, to the extent possible, choosing the treating physician; accepting or rejecting diagnostic and therapeutic procedures and, if applicable, collaborating to their performance; adhering to the accepted treatment; watching for the appearance of adverse effects, reporting them and monitoring the course of the disease. If these faculties are recognized as patient rights, can he/she be granted or not the right to responsibly self-medicate?

\section{Advantages and disadvantages of self-medication}

Given that self-medication and self-prescription are everyday practices, it would appear a good decision trying to regulate rather than demonizing them by discouraging the latter and encouraging the former under certain rules and based on health education. To the extent the public learns to handle OTC products, their benefits can be taken advantage of and their drawbacks reduced.

Self-medication has the advantage that it reduces the burden on health services caused by minor, trivial ailments, which delay the care of those who require these services but cannot receive them because health facilities are overwhelmed. On the other hand, given that OTC drugs are relatively innocuous and have an acceptable safety profile, have been in the market for many years without being associated with major issues, and help treating common symptoms of mild severity, it would seem sufficient making sure that doses are not exceeded and contraindications taken into account. In addition, access to medication is simplified, individual participation in health care is promoted, costs are reduced and the time required for medical consultation is spared. There is no entirely innocuous drug, but something similar can be said about certain foods, cosmetics, pesticides, alcohol and other products in which individual authorization is not required for their use.

Since the Law requires that OTC drugs have an insert indicating the dosage, instructions for use and precautions, it is assumed that it is the consumer's responsibility to follow these instructions, as with other products. The problem is that patients do not always read these inserts and prefer, as it occurs with electrical appliances user manuals, to learn their use by trial and error, which entails evident risks.
The responsibility of physicians and health authorities cannot be evaded, but patients have to assume their own in health preservation and care of diseases; ultimately, the patient is the main responsible. In a universal access system with broad capacity, even for trivial disorders, without undermining the care of more serious problems, self-medication would be less useful. Self-medication does not exclude the physician's participation, but it does postpone it when it is not necessary; this could be a disadvantage, since in evolving ailments, valuable time for timely intervention can be lost. In these cases, the physician can act as self-medicating patients' advisor and educator.

On the other hand, self-prescription has all the disadvantages, except in commercial terms for unethical pharmacies and pharmaceutical companies, which consent and promote it out of convenience.

The issue of self-medication and self-prescription is controversial, but its analysis must be detached form personal and professional interests, from thoughtless traditions and focus on current best interest of patients and society.

\section{Conflicts of interest}

The authors declare that they have no conflicts of interest.

\section{Funding}

The authors did not receive any sponsoring to carry out this article.

\section{Ethical disclosures}

Protection of human and animal subjects. The authors declare that no experiments were performed on humans or animals for this research.

Confidentiality of data. The authors declare that no patient data appear in this article.

Right to privacy and informed consent. The authors declare that no patient data appear in this article.

\section{References}

1. Academia Nacional de Medicina de México. Comité de Ética y Transparencia de los médicos con la industria farmacéutica (CETREMI). Gac Med Mex. 2015;151:293.

2. Lifshitz A, Arrieta O, Campillo C, Burgos R, Celis MA, De la Llata M, et al. Libertad de prescripción médica. Gac Med Mex. 2019;155:202-203. 